\title{
Exploring Host Genetic Polymorphisms Involved in SARS-CoV Infection Outcomes: Implications for Personalized Medicine in COVID-19
}

\author{
Omar Ramos-Lopez $\mathbb{D},{ }^{1}$ Lidia Daimiel $\mathbb{D},{ }^{2}$ Ana Ramírez de Molina $\mathbb{D},^{3}$ \\ Diego Martínez-Urbistondo $\mathbb{D}^{4},{ }^{4}$ Juan A. Vargas $\mathbb{D}^{5,}, 6$ and J. Alfredo Martínez $\mathbb{D}^{7,8,9,10}$ \\ ${ }^{1}$ Faculty of Medicine and Psychology, Autonomous University of Baja California, Tijuana, Baja California, Mexico \\ ${ }^{2}$ Nutritional Control of the Epigenome Group, IMDEA Food, CEI UAM + CSIC, Madrid, Spain \\ ${ }^{3}$ Molecular Oncology and Nutritional Genomics of Cancer, IMDEA-Food Institute, CEI UAM + CSIC, Madrid, Spain \\ ${ }^{4}$ Hospital Universitario HM Sanchinarro, Madrid, Spain \\ ${ }^{5}$ Servicio de Medicina Interna, Hospital Universitario Puerta de Hierro Majadahonda, Madrid, Spain \\ ${ }^{6}$ Facultad de Medicina, Departamento de Medicina, Universidad Autónoma de Madrid, Spain \\ ${ }^{7}$ Department of Nutrition, Food Science, Physiology and Toxicology, Centre for Nutrition Research, University of Navarra, \\ Pamplona, Spain \\ ${ }^{8}$ Navarra Institute for Health Research (IdiSNA), Pamplona, Spain \\ ${ }^{9}$ Spanish Biomedical Research Centre in Physiopathology of Obesity and Nutrition (CIBERObn), Spain \\ ${ }^{10}$ Precision Nutrition and Cardiometabolic Health, Madrid Institute of Advanced Studies (IMDEA-Food Institute), Madrid, Spain
}

Correspondence should be addressed to Omar Ramos-Lopez; os_mar6@hotmail.com

Received 17 June 2020; Revised 19 September 2020; Accepted 13 October 2020; Published 22 October 2020

Academic Editor: Paulo M. Pinto

Copyright (c) 2020 Omar Ramos-Lopez et al. This is an open access article distributed under the Creative Commons Attribution License, which permits unrestricted use, distribution, and reproduction in any medium, provided the original work is properly cited.

Objective. To systematically explore genetic polymorphisms associated with the clinical outcomes in SARS-CoV infection in humans. Methods. This comprehensive literature search comprised available English papers published in PubMed/Medline and SCOPUS databases following the PRISMA-P guidelines and PICO/AXIS criteria. Results. Twenty-nine polymorphisms located in 21 genes were identified as associated with SARS-CoV susceptibility/resistance, disease severity, and clinical outcomes predominantly in Asian populations. Thus, genes implicated in key pathophysiological processes such as the mechanisms related to the entry of the virus into the cell and the antiviral immune/inflammatory responses were identified. Conclusions. Although caution must be taken, the results of this systematic review suggest that multiple genetic polymorphisms are associated with SARS-CoV infection features by affecting virus pathogenesis and host immune response, which could have important applications for the study and understanding of genetics in SARS-CoV-2/COVID-19 and for personalized translational clinical practice depending on the population studied and associated environments.

\section{Background}

Coronaviruses (CoVs) have become one of the leading pathogens of the latest emerging outbreaks of respiratory disease, representing a serious public health burden worldwide [1]. A novel coronavirus was identified to play a crucial role in the severe acute respiratory syndrome (SARS) in 2003 [2]. Later, the severe acute respiratory syndrome coronavirus-2 (SARS-
CoV-2), which produces the disease coronavirus-2019 (COVID-19), has emerged in December 2019. This new virus appears to be highly contagious and has spread rapidly throughout the world, reaching a pandemic state, with important social and health system costs [3].

CoVs are a large family of positive-stranded, singlestranded, enveloped RNA viruses [4]. Relevant pathophysiological mechanisms of CoV, including SARS-CoV and SARS- 
CoV-2, are related to an exacerbated immunological response that the viral infection produces in the host [5]. In some cases, this reaction is excessive (inflammatory cytokine storm), triggering an extensive tissue damage and body dysfunction [6]. The clinical manifestations of this infection include typical symptoms such as cough, fever, asthenia, and mild respiratory distress. However, more serious respiratory injuries include pneumonia, acute respiratory distress syndrome, and respiratory failure, accompanied by inflammatory outcomes affecting adipokines and other mediators [6]. Furthermore, recent investigations have reported the presence of neurological, renal, hepatic, and cardiac complications in some patients [7]. On the other hand, a group of patients are asymptomatic or with very mild manifestations during the course of the infection, with a relatively short recovery time [8].

Certain risk factors for the chronicity and severity of COVID-19 infection have been reported, including age (over 60 years), male gender, and the presence of concomitant metabolic conditions such as obesity, diabetes, and hypertension $[9,10]$. Nevertheless, there is a constant search for biological factors associated with the evolution of COVID-19. Evidence suggests that genetic factors may influence the onset and progression of infectious diseases [11]. In this context, a number of genetic variants, mainly single nucleotide polymorphisms (SNPs), have been associated with the susceptibility/resistance to viral respiratory infections [12]. Until now, the specific role of the genetic make-up in SARS-CoV2/COVID-19 disease has been insufficiently analyzed, although proinflammatory-related pathways have been involved [6].

Understanding the host genetic factors involved in SARS$\mathrm{CoV}$ infection could contribute to the identification of new therapeutic tools for advancing in the prevention and clinical management of this disease through a personalized medicine approach [13]. Due to the lack of information concerning genetics and SARS-CoV-2/COVID-19 infection, the aim of the present review was to systematically explore the genetic polymorphisms associated with the clinical outcomes in SARS-CoV infection in humans in order to translate this information to SARS-CoV-2/COVID-19 research and clinical implementation.

\section{Methods}

A systematic review was performed in March 2020 to analyze the association of genetic polymorphisms with SARS-CoV infection outcomes. The methodological procedures of this systematic review were performed according to the Preferred Reporting Items for Systematic Reviews and Meta-Analyses Protocols (PRISMA-P) guidelines [14]. Observational (cross-sectional, cohort, or case-control) studies exploring the role of host genetic polymorphisms in SARS-CoV disease (infection susceptibility, disease progression, and clinical outcomes) in adult subjects were included. Articles written only in the English language were selected. Duplicates, reviews, clinical trials, in vitro assays, animal experiments, and human studies reporting negative results or focused on other infectious diseases or genetic factors were excluded.
The comprehensive literature search encompassed available papers compiled in PubMed/Medline and SCOPUS databases without a period of time or study population restrictions. Advanced search techniques for each database were used to make the search more efficient (i.e., "MeSH" and "tiab" terms). The keywords used were as follows: ("genetic polymorphisms") OR ("genetic variations") OR ("gene polymorphisms") OR ("genetic variations") AND (“SARS-CoV”) OR (“SARS CoV”) (“SARS coronavirus") OR ("SARS virus"). The reference sections of the included articles were also scrutinized. This search strategy was replicated at different times to guarantee reproducibility. Moreover, two researchers performed independently the research. Using these terms, a total of 202 articles were identified. Five additional articles were added from reviews, which did not appear in this first stage (Figure 1). First, duplicates were eliminated $(n=132)$, obtaining 75 records for the eligibility criteria assessment. After the duplicates were removed, the titles, abstracts, and keywords of 75 manuscripts were screened, excluding those that did not meet the eligibility criteria $(n=41)$ or reported negative/inconsistent findings $(n=8)$. Finally, 26 articles were included in the current analyses (Figure 1).

The most relevant information about each of the 26 selected studies included in the present review was analyzed using the Population, Intervention, Comparison, Outcome (PICO) criteria [15]. The selected articles met at least 3 inclusion criteria (Supplementary Table 1). The quality assessment of the analyzed studies was performed using the Appraisal tool for Cross-Sectional Studies (AXIS tool), a validated 20-point questionnaire with 6 subdomains (introduction, methods, results, discussion, and others) addressing study quality and reporting encompassing study design, sample size justification, target population, sampling frame, sample selection, measurement of validity/reliability, and overall methods [16]. Because the AXIS tool does not provide a numerical scale for assessing the quality of the study, subjective assessments by the authors are required [16]. Thus, the authors of this study performed a consensus procedure to evaluate the general and overall quality of records in order to select those to be included in the systematic review. The screening was completed with references coming from citations of the 26 selected studies. The results of the AXIS tool are summarized (Supplementary Table 2).

\section{Results}

The present systematic review revealed that 29 polymorphisms located in 21 genes were associated with SARS-CoV susceptibility/resistance, disease severity, and clinical manifestations/outcomes (Table 1).

Available studies used mainly a gene-candidate approach to select those genes involved in disease pathogenesis and phenotypes based on a priori knowledge. Thus, genes implicated in key physiological processes such as the mechanisms related to the entry of the virus into the cell and the antiviral immune/inflammatory response were found (Table 1). 


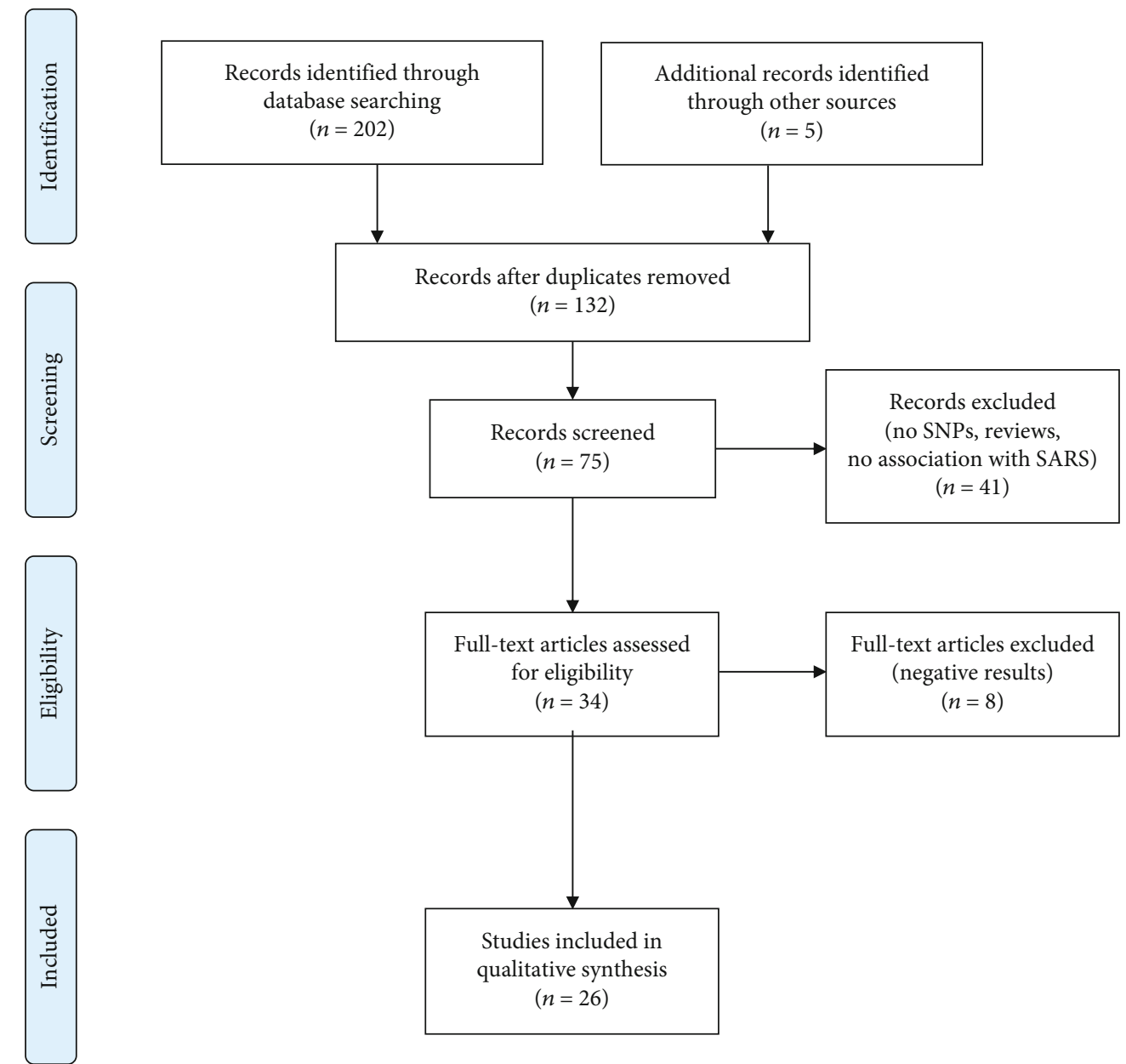

FIgURE 1: PRISMA flow diagram summarizing the selection of papers included in this systematic review.

Of note, research was predominantly performed in Asian populations, including Chinese, Vietnamese, and Taiwanese populations. Moreover, genetic polymorphisms were mainly SNPs in coding and promoter regions, although insertion/deletion and tandem repeats were also described.

For instance, Chinese individuals homozygous for the tandem repeat domain in exon 4 of the CLEC4M gene were less susceptible to SARS infection [17]. Also, the insertion/deletion (I/D) polymorphism in the ACE1 gene was associated with the progression of pneumonia in SARS patients [18]. Both genes are involved in virus entry.

The rest of the genetic polymorphisms were located in cytokine and chemokine genes implicated in the immune response and inflammatory processes. For example, the IFN- $\gamma+874 \mathrm{~A}$ allele was associated with the susceptibility to develop SARS in two independent populations $[19,20]$. Also, the minor alleles of the $-88 \mathrm{G}>\mathrm{T}$ and $-123 \mathrm{C}>\mathrm{A} M x \mathrm{~A}$ promoter SNPs were significantly associated with a lower risk of SARS-CoV infection in Chinese [21]. Nevertheless, the G/T SNP at position -88 in the promoter region of this gene was associated with SARS-CoV disease progression [22].

Genetic variations in the inflammatory TNF- $\alpha$ gene were also screened. Thus, whereas the CT genotype at the TNF- $\alpha$ -204 locus of this gene was found to be associated with a pro- tective effect on SARS, a higher A allele frequency of the TNF- $\alpha-308 \mathrm{G} / \mathrm{A}$ polymorphism was found in the SARS population when compared with healthy controls [23]. Moreover, the prevalence of the CD14-159CC polymorphism was significantly higher in patients with severe SARS than in those with mild stages of the disease or controls [24].

The distribution of HLA alleles has been widely used as a strategy in the search for the etiology of infectious diseases. In this sense, three genetic polymorphisms in the $H L A-B$ gene were related to different SARS-CoV outcomes, including infection predisposition, a protective phenotype [25], and severe forms of the disease [26]. In addition, the $\mathrm{Cw} * 0801$ and $\mathrm{Cw} * 1502$ variants in the HLA-Cw gene were associated with SARS risk [27] and SARS resistance [28] in Taiwanese, respectively.

\section{Discussion}

Personalized medicine involves a balanced knowledge of genotype, phenotype, and clinical features of the patient [13], where susceptibility to exacerbated infection is often dependent. Similar to other viral diseases, the first step in SARS-CoV infection includes the attachment of the virus to the host cell receptors [29]. In the present review, genetic 
TABLE 1: List of relevant polymorphisms in genes implicated in the susceptibility and progression to SARS-CoV infection.

\begin{tabular}{|c|c|c|c|c|c|c|}
\hline Gene & SNP & Risk/protective allele & Outcome & Frequency & Population & Reference \\
\hline \multicolumn{7}{|c|}{ Mechanisms of entry of the virus into the cell } \\
\hline$A C E 1$ & Insertion/deletion (I/D) & $\mathrm{D}$ & Higher frequency of hypoxemia & 0.33 & Vietnamese & {$[18]$} \\
\hline CD209 & $-336 \mathrm{~A}>\mathrm{G}$ & G & $\begin{array}{l}\text { Lower blood levels of lactate- } \\
\text { dehydrogenase (an independent } \\
\text { prognostic indicator for severity } \\
\text { of SARS-CoV infection) }\end{array}$ & 0.10 & Chinese & {$[47,48]$} \\
\hline CLEC4M & $\begin{array}{l}\text { Tandem repeat } \\
\text { domain in exon } 4\end{array}$ & Homozygotes & $\begin{array}{l}\text { Lower susceptibility to } \\
\text { SARS-CoV infection incidence }\end{array}$ & 0.46 & Chinese & {$[17]$} \\
\hline \multicolumn{7}{|c|}{ Immune response/inflammation phenomena } \\
\hline ICAM-3 & Asp143Gly & Gly & $\begin{array}{l}\text { Higher lactate dehydrogenase levels } \\
\text { and lower white blood cell counts }\end{array}$ & $0.10-0.17$ & Chinese & {$[49,50]$} \\
\hline$I F N-\gamma$ & $+874 \mathrm{~A} / \mathrm{T}$ & A & $\begin{array}{c}\text { Higher susceptibility to SARS-CoV } \\
\text { infection incidence }\end{array}$ & 0.83 & Chinese & {$[19,20]$} \\
\hline RANTES & $-28 \mathrm{C} / \mathrm{G}$ & G & $\begin{array}{l}\text { Higher susceptibility to SARS-CoV } \\
\text { infection incidence and increased } \\
\text { risk of death }\end{array}$ & 0.21 & Chinese & {$[20,51]$} \\
\hline$O A S-1$ & A/G SNP in exon 3 & G & $\begin{array}{l}\text { Higher susceptibility to SARS-CoV } \\
\text { infection incidence }\end{array}$ & 0.48 & Vietnamese & {$[22]$} \\
\hline$O A S-1$ & $\begin{array}{l}\text { A/G SNP at the } 3 \text { UTR } \\
347 \text { locus of the exon } 8\end{array}$ & G & $\begin{array}{l}\text { Lower susceptibility to SARS-CoV } \\
\text { infection incidence }\end{array}$ & 0.24 & Chinese & {$[52]$} \\
\hline$M x A$ & $-123 \mathrm{C}>\mathrm{A}$ & A & $\begin{array}{l}\text { Lower susceptibility to SARS-CoV } \\
\text { infection incidence }\end{array}$ & 0.11 & Chinese & {$[21]$} \\
\hline$M x A$ & $\begin{array}{l}\mathrm{G} / \mathrm{T} \mathrm{SNP} \text { at position }-88 \\
\text { in the promoter region }\end{array}$ & G & Higher frequency of hypoxemia & $0.76-0.82$ & $\begin{array}{l}\text { Chinese, } \\
\text { Vietnamese }\end{array}$ & {$[21,22]$} \\
\hline$M x A$ & $\begin{array}{l}\text { G/T SNP at position }-88 \\
\text { in the promoter region }\end{array}$ & GT genotype & $\begin{array}{l}\text { Higher susceptibility to } \\
\text { SARS-CoV infection incidence }\end{array}$ & $0.73-0.81$ & Chinese & {$[52,53]$} \\
\hline$I L-12 R B 1$ & $+1664 \mathrm{C} / \mathrm{T}$ & $\mathrm{T}$ & $\begin{array}{l}\text { Higher susceptibility to SARS-CoV } \\
\text { infection incidence }\end{array}$ & 0.29 & Chinese & {$[54]$} \\
\hline FcgRIIa & H131R & $\mathrm{R}$ & $\begin{array}{l}\text { Associated with a severe course } \\
\text { of the disease (requiring treatment } \\
\text { in an intensive care unit) }\end{array}$ & 0.34 & Chinese & {$[55]$} \\
\hline$M L B$ & Codon 54 variant $(\mathrm{A} / \mathrm{B})$ & $\mathrm{B}$ & $\begin{array}{c}\text { Higher susceptibility to SARS-CoV } \\
\text { infection incidence }\end{array}$ & $0.34-0.35$ & Chinese & {$[56,57]$} \\
\hline CCL2 & G-2518A & G & $\begin{array}{l}\text { Higher susceptibility to SARS-CoV } \\
\text { infection incidence }\end{array}$ & 0.80 & Chinese & {$[57]$} \\
\hline AHSG & $-799 \mathrm{~A} / \mathrm{T}$ & $\mathrm{T}$ & $\begin{array}{c}\text { Higher susceptibility to SARS-CoV } \\
\text { infection incidence }\end{array}$ & 0.21 & Chinese & {$[58]$} \\
\hline$T N F-\alpha$ & -204 & CT genotype & $\begin{array}{l}\text { Lower susceptibility to SARS-CoV } \\
\text { infection incidence and increased } \\
\text { risk of femoral head necrosis }\end{array}$ & 0.05 & Chinese & {$[23]$} \\
\hline$T N F-\alpha$ & $-308 \mathrm{G} / \mathrm{A}$ & A & Increased risk of femoral head necrosis & 0.06 & Chinese & {$[23]$} \\
\hline CD14 & $-159 \mathrm{C} / \mathrm{T}$ & $\mathrm{C}$ & $\begin{array}{l}\text { Associated with a severe course } \\
\text { of the disease (requiring treatment } \\
\text { in an intensive care unit) }\end{array}$ & 0.31 & Chinese & {$[24]$} \\
\hline$H L A-B$ & $\mathrm{~B} * 0703$ & $\mathrm{~B} * 0703$ & $\begin{array}{l}\text { Higher susceptibility to SARS-CoV } \\
\text { infection incidence }\end{array}$ & 0.11 & Chinese & {$[25]$} \\
\hline$H L A-D R B 1$ & $\mathrm{DRB} 1 * 0301$ & $\mathrm{DRB} 1 * 0301$ & $\begin{array}{l}\text { Lower susceptibility to SARS-CoV } \\
\text { infection incidence }\end{array}$ & 0.01 & Chinese & {$[25]$} \\
\hline$H L A-B$ & $\mathrm{~B} * 4601$ & $\mathrm{~B} * 4601$ & $\begin{array}{l}\text { Associated with severe cases of } \\
\text { SARS-CoV infection (deceased } \\
\text { or intubated patients) }\end{array}$ & 0.60 & Taiwanese & {$[26]$} \\
\hline$H L A-D R B 4$ & $\mathrm{DRB} 4 * 01010101$ & $\mathrm{DRB} 4 * 01010101$ & $\begin{array}{l}\text { Higher susceptibility to SARS-CoV } \\
\text { infection incidence }\end{array}$ & 0.51 & Chinese & [59] \\
\hline$H L A-B$ & $\mathrm{~B} * 1502$ & $\mathrm{~B} * 1502$ & $\begin{array}{l}\text { Lower susceptibility to SARS-CoV } \\
\text { infection incidence }\end{array}$ & 0.26 & Chinese & {$[59]$} \\
\hline$H L A-D R B 3$ & $\mathrm{DRB} 3 * 030101$ & $\mathrm{DRB} 3 * 030101$ & $\begin{array}{l}\text { Lower susceptibility to SARS-CoV } \\
\text { infection incidence }\end{array}$ & 0.28 & Chinese & {$[59]$} \\
\hline$H L A-D R B 1$ & $\mathrm{DRB} 1 * 1202$ & $\mathrm{DRB} 1 * 1202$ & $\begin{array}{l}\text { Higher susceptibility to SARS-CoV } \\
\text { infection incidence }\end{array}$ & 0.47 & Vietnamese & {$[60]$} \\
\hline
\end{tabular}


TABLe 1: Continued.

\begin{tabular}{|c|c|c|c|c|c|c|}
\hline Gene & SNP & Risk/protective allele & Outcome & Frequency & Population & Reference \\
\hline$H L A-C w$ & $\mathrm{Cw} * 0801$ & $\mathrm{Cw} * 0801$ & $\begin{array}{l}\text { Higher susceptibility to SARS-CoV } \\
\text { infection incidence }\end{array}$ & 0.23 & Taiwanese & [27] \\
\hline$H L A-C w$ & $\mathrm{Cw} * 1502$ & $\mathrm{Cw} * 1502$ & $\begin{array}{l}\text { Lower susceptibility to SARS-CoV } \\
\text { infection incidence }\end{array}$ & 0.10 & Taiwanese & {$[28]$} \\
\hline$H L A-D R$ & $\mathrm{DR} * 0301$ & $\mathrm{DR} * 0301$ & $\begin{array}{l}\text { Lower susceptibility to SARS-CoV } \\
\text { infection incidence }\end{array}$ & 0.11 & Taiwanese & [28] \\
\hline
\end{tabular}

variants in ACE1, CLEC4M, and CD209 genes were associated with SARS-CoV-related disease pathogenesis. Particularly, the angiotensin-converting enzyme 2 (ACE2, a homologue of ACE1) has been identified as a functional receptor for SARS-CoV [30]. Also, the C-type lectin domain family 4 member M (CLEC4M, also known as L-SIGN) was recognized as a binding receptor for this virus [31]. CD209 (also known as DC-SIGN) shares amino acid identity with CLEC4M, which was involved in facilitating SARS-CoV viral transmission to susceptible cells [32]. These findings demonstrate the important functions of these molecules in the virus entry. Nevertheless, two additional studies failed to demonstrate a relationship between ACE2 polymorphisms and SARS-CoV outcome in Asians so far [33, 34], emphasizing the need for future research in other populations.

Virus survival and virus-induced disease outcomes (including SARS-CoV) are commonly linked to the modulation of the immune response in the host [35]. As expected, in this review, genetic polymorphisms in genes involved in immunocompetence/inflammatory pathways were found (ICAM-3, IFN- $\gamma$, RANTES, OAS-1, MxA, IL-12 RB1, FcgRIIa, $M L B, C C L 2, A H S G, T N F-\alpha, C D 14)$. Most of them are cytokines or chemokines that are known to be important mediators of early defense against infections, activating protective mechanisms in infected cells [36]. These processes occur during the immune response driven by the SARS-CoV infection and comprise $\mathrm{T}$ cell stimulation (ICAM-3, IL-12 RB1), macrophage activation/deactivation $(I F N-\gamma, A H S G)$, cell trafficking (RANTES, CCL2), RNA degradation and the inhibition of viral replication (OAS1, $M \times A)$, link between humoral and cell-mediated immune reaction $(F c g R I I a)$, virus binding $(M L B)$, and inflammation (TNF- $\alpha, C D 14)$ (http://www.genecards.org).

Genetic variations in HLA class I or II genes have been often associated with susceptibility/resistance to a wide range of infections, including SARS-CoV [37]. Accordingly, the genes of the HLA complex were associated with SARS-CoV outcomes in this study (HLA-B, HLA-DRB1, HLA-DRB4, $H L A-D R B 3, H L A-C w)$. HLA play a critical role in the presentation of antigenic peptides to $\mathrm{T}$ cells, orchestrating an immune response aimed at removing nonself material via neutralization of antibodies, cytokines, and activated cytotoxic $\mathrm{T}$ cells [38].

Robust evidence support that genetic variation in human populations contributes to the onset and development of several chronic diseases, including those of an infectious nature [39]. The results of this systematic review show that research exploring the genetic contribution to SARS-CoV infection was predominantly performed in Asian populations, which may be related to its epidemiological origin in China in 2002 [40]. However, allele and genotype frequencies of genetic variants may vary depending on region; therefore, the results should not be extrapolated to other populations without prior exploration. Therefore, further investigation is required to determine the pattern of distribution of these and other candidate polymorphisms in other groups as well as confirm associations with SARS-CoV outcomes. This knowledge is particularly important in populations with heterogenic heritages exposed to absolutely different environmental factors. An example could be Latin American countries, including Mexico, which have an admixture genome with Amerindian, European, and African ancestries; a high prevalence of obesity; and associated comorbidities as well as the adoption of an unhealthy lifestyle (high-fat/sugar diet and physical inactivity) that could exacerbate the outcome of viral infections [41]. Or even some SNPs that have not been associated with SARS-CoV disease outcomes in the Asian population could become a significant association in other populations because of a strong environmental pressure. Thus, we cannot rule out the possibility that other SNPs in other genes could play a role in susceptibility to SARS$\mathrm{CoV}$ infection in these populations.

In this context, personalized medicine is an integrative therapeutic approach that considers conventional factors (age, gender, clinical phenotype), as well as emerging genetics and interactions with environmental factors to individualize prevention, diagnosis, treatments, and prognosis [42]. Applying the principles of personalized medicine in the current care schemes for the control of infectious diseases (i.e., SARS-CoV) could allow the identification of genetically susceptible groups, disease risk prediction, and personalized therapies to reduce infection-related complications, high mortality rates, and the optimization of economic resources for health care and individualized management of inflammation (Figure 2).

Currently, the high incidence of SARS-CoV-2/COVID19 around the world, the speed of its spread, and the absence of a specific drug for its pharmacological management emphasize the need to identify risk factors associated with the dynamics of infection and disease progression in order to mitigate its negative impact on the society. A better understanding of the relationship between the genetic make-up and SARS-CoV-2/COVID-19 will provide new insights into the disease pathogenesis by explaining particular phenotypes and clinical responses. Moreover, this knowledge will also aid in identifying biomarkers as potential therapeutic targets for evaluating the efficacy of genome-based interventions and other personalized treatments within the new era of precision medicine. 


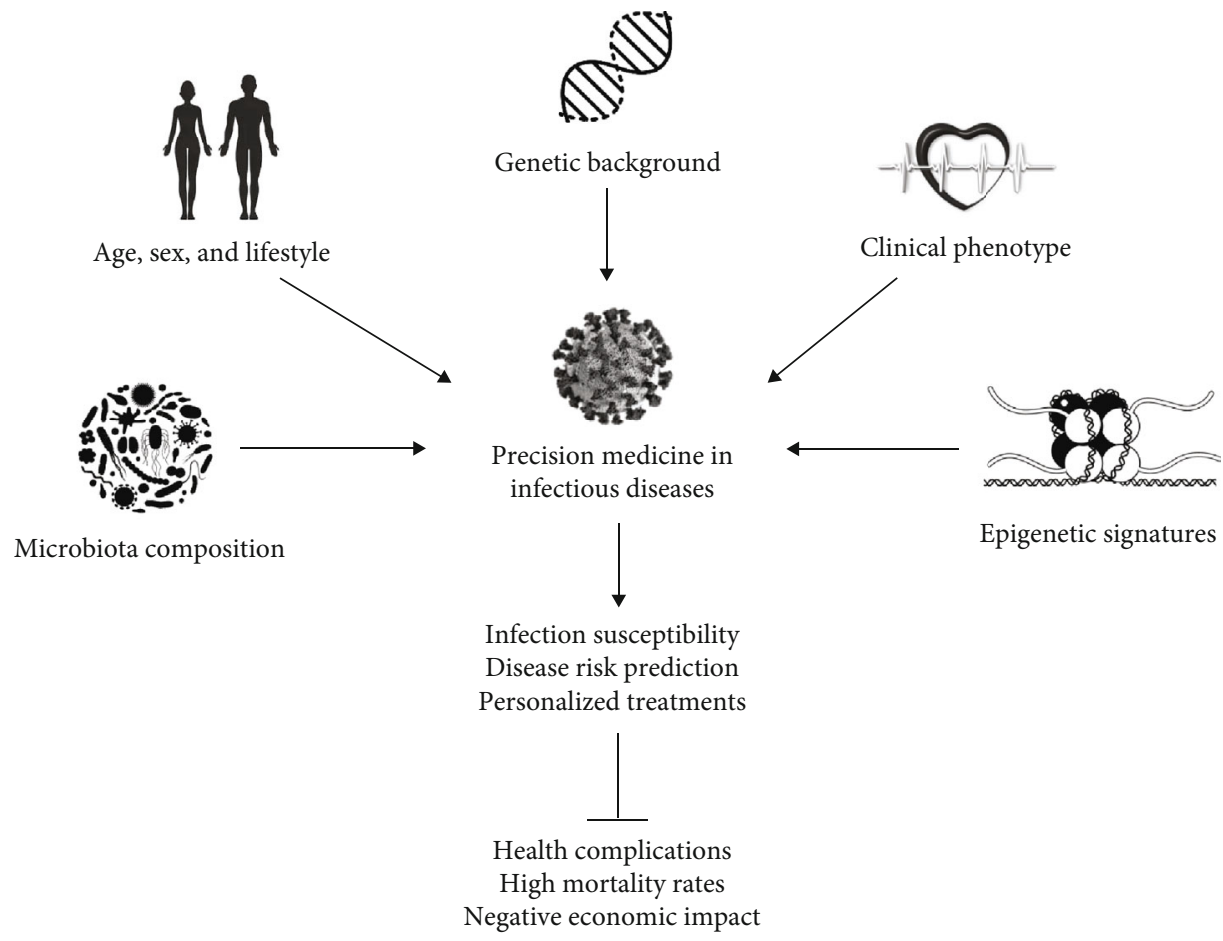

FIGURE 2: Genetic background and other precision parameters as important predictors of SARS-CoV infection and personalized translational medicine interventions.

In addition to the polymorphisms analyzed in this review, new genetic variants affecting SARS-CoV and SARS-CoV-2/COVID-19 susceptibility need to be further explored as well as the interplay of other emerging parameters of individualization such as epigenetic signatures, metabolomic fingerprints, metagenomic data, and lifestyle factors through an integrative holistic approach [43]. Potential genexdrug or genexinflammation interactions also deserve further investigation. In this regard, drugs targeting the inflammatory cytokines IL-1 and IL- 6 have been proposed to reduce extreme immune reaction to the virus and extensive tissue damage $[44,45]$, where genetics may play a pivotal role. Additionally, genotyping of virus isolates to detect specific multiple mutations is of great importance for the understanding of the evolution and transmission of SARS-CoV infections as well as for vaccine development and disease control [46].

\section{Conclusion}

Although caution must be taken, the results of this systematic review suggest that multiple genetic polymorphisms are associated with SARS-CoV infection outcomes (susceptibility and severity, hospitalization, ICU stays, and medications) by affecting virus pathogenesis and host immune response, which could have important applications for the study and understanding of genetics in SARS-CoV-2/COVID-19 and for personalized translational clinical practice depending on the population studied and associated environments.

\section{Data Availability}

All data are available in the article.

\section{Conflicts of Interest}

The authors declare that there is no conflict of interest regarding the publication of this paper.

\section{Authors' Contributions}

ORL and JAM performed the search of articles and wrote the draft of the manuscript. LD, ARM, DMU, and JAV contributed to the analysis and critical interpretation of the data. All authors read and approved the final manuscript.

\section{Acknowledgments}

The support from CIBERObn, IMDEA-Food Institute, and HM hospitals is gratefully acknowledged.

\section{Supplementary Materials}

Supplementary Table 1. PICO criteria used for the inclusion and exclusion of screened studies. Supplementary Table 2. Quality assessment of the individual studies by applying the AXIS tool. (Supplementary Materials)

\section{References}

[1] E. de Wit, N. van Doremalen, D. Falzarano, and V. J. Munster, "SARS and MERS: recent insights into emerging 
coronaviruses," Nature Reviews Microbiology, vol. 14, no. 8, pp. 523-534, 2016.

[2] T. G. Ksiazek, D. Erdman, C. S. Goldsmith et al., "A novel coronavirus associated with severe acute respiratory syndrome," The New England Journal of Medicine, vol. 348, no. 20, pp. 1953-1966, 2003.

[3] S. Hamid, M. Y. Mir, and G. K. Rohela, "Novel coronavirus disease (COVID-19): a pandemic (epidemiology, pathogenesis and potential therapeutics)," New Microbes and New Infections, vol. 35, article 100679, 2020.

[4] R. Madhugiri, M. Fricke, M. Marz, and J. Ziebuhr, "Coronavirus cis-acting RNA elements," Advances in Virus Research, vol. 96, pp. 127-163, 2016.

[5] M. Merad and J. C. Martin, "Pathological inflammation in patients with COVID-19: a key role for monocytes and macrophages," Nature Reviews Immunology, vol. 20, no. 6, pp. 355362, 2020.

[6] Q. Ye, B. Wang, and J. Mao, "The pathogenesis and treatment of the 'Cytokine Storm' in COVID-19," The Journal of Infection, vol. 80, no. 6, pp. 607-613, 2020.

[7] D. Atri, H. K. Siddiqi, J. P. Lang, V. Nauffal, D. A. Morrow, and E. A. Bohula, "COVID-19 for the cardiologist: basic virology, epidemiology, cardiac manifestations, and potential therapeutic strategies," JACC: Basic to Translational Science, vol. 5, no. 5, pp. 518-536, 2020.

[8] Y. Chen, Q. Liu, and D. Guo, "Emerging coronaviruses: genome structure, replication, and pathogenesis," Journal of Medical Virology, vol. 92, no. 4, pp. 418-423, 2020.

[9] M. Watanabe, R. Risi, D. Tuccinardi, C. J. Baquero, S. Manfrini, and L. Gnessi, "Obesity and SARS-CoV-2: a population to safeguard," Diabetes/Metabolism Research and Reviews, vol. 36, no. 7, article e3325, 2020.

[10] P. Conti and A. Younes, "Coronavirus COV-19/SARS-CoV-2 affects women less than men: clinical response to viral infection," Journal of Biological Regulators and Homeostatic Agents, vol. 34, no. 2, pp. 339-343, 2020.

[11] A. V. S. Hill, "Evolution, revolution and heresy in the genetics of infectious disease susceptibility," Philosophical Transactions of the Royal Society of London. Series B, Biological Sciences, vol. 367, no. 1590, pp. 840-849, 2012.

[12] I. Patarčić, A. Gelemanović, M. Kirin et al., "The role of host genetic factors in respiratory tract infectious diseases: systematic review, meta-analyses and field synopsis," Scientific Reports, vol. 5, no. 1, 2015.

[13] O. Ramos-Lopez, F. I. Milagro, H. Allayee et al., "Guide for current nutrigenetic, nutrigenomic, and nutriepigenetic approaches for precision nutrition involving the prevention and management of chronic diseases associated with obesity," Journal of Nutrigenetics and Nutrigenomics, vol. 10, no. 1-2, pp. 43-62, 2017.

[14] A. Liberati, D. G. Altman, J. Tetzlaff et al., "The PRISMA statement for reporting systematic reviews and meta-analyses of studies that evaluate health care interventions: explanation and elaboration," Journal of Clinical Epidemiology, vol. 62, no. 10, pp. e1-34, 2009.

[15] F. Boudin, J. Y. Nie, J. C. Bartlett, R. Grad, P. Pluye, and M. Dawes, "Combining classifiers for robust PICO element detection," BMC Medical Informatics and Decision Making, vol. 10, no. 1, p. 29, 2010.

[16] M. J. Downes, M. L. Brennan, H. C. Williams, and R. S. Dean, "Development of a critical appraisal tool to assess the quality of cross-sectional studies (AXIS)," BMJ Open, vol. 6, no. 12, article e011458, 2016.

[17] V. S. F. Chan, K. Y. K. Chan, Y. Chen et al., "Homozygous LSIGN (CLEC4M) plays a protective role in SARS coronavirus infection," Nature Genetics, vol. 38, no. 1, pp. 38-46, 2006.

[18] S. Itoyama, N. Keicho, T. Quy et al., "ACE1 polymorphism and progression of SARS," Biochemical and Biophysical Research Communications, vol. 323, no. 3, pp. 1124-1129, 2004.

[19] W. P. Chong, W. K. E. Ip, G. H. W. Tso et al., "The interferon gamma gene polymorphism $+874 \mathrm{~A} / \mathrm{T}$ is associated with severe acute respiratory syndrome," BMC Infectious Diseases, vol. 6, no. 1, p. 82, 2006.

[20] Y. L. Lau and J. S. Peiris, "Association of cytokine and chemokine gene polymorphisms with severe acute respiratory syndrome," Hong Kong Medical Journal, vol. 15, Supplement 2, pp. 43-46, 2009.

[21] J. C. Y. Ching, K. Y. K. Chan, E. H. L. Lee et al., "Significance of the myxovirus resistance A (MxA) gene $-123 \mathrm{C}>\mathrm{a}$ singlenucleotide polymorphism in suppressed interferon $\beta$ induction of severe acute respiratory syndrome coronavirus infection," The Journal of Infectious Diseases, vol. 201, no. 12, pp. 1899-1908, 2010.

[22] E. Hamano, M. Hijikata, S. Itoyama et al., "Polymorphisms of interferon-inducible genes OAS-1 and MxA associated with SARS in the Vietnamese population," Biochemical and Biophysical Research Communications, vol. 329, no. 4, pp. 12341239, 2005.

[23] S. Wang, M. Wei, Y. Han et al., "Roles of TNF- $\alpha$ gene polymorphisms in the occurrence and progress of SARS-Cov infection: a case-control study," BMC Infectious Diseases, vol. 8, no. 1, p. 27, 2008.

[24] F. F. Yuan, I. Boehm, P. K. S. Chan et al., "High prevalence of the CD14-159CC genotype in patients infected with severe acute respiratory syndrome-associated coronavirus," Clinical and Vaccine Immunology, vol. 14, no. 12, pp. 1644-1645, 2007.

[25] M. H. L. Ng, K. M. Lau, L. Li et al., "Association of humanleukocyte-antigen class I $(\mathrm{B} * 0703)$ and class II $(\mathrm{DRB} 1 * 0301)$ genotypes with susceptibility and resistance to the development of severe acute respiratory syndrome," The Journal of Infectious Diseases, vol. 190, no. 3, pp. 515-518, 2004.

[26] M. Lin, H. K. Tseng, J. A. Trejaut et al., "Association of HLA class I with severe acute respiratory syndrome coronavirus infection," BMC Medical Genetics, vol. 4, no. 1, p. 9, 2003.

[27] Y. M. A. Chen, S. Y. Liang, Y. P. Shih et al., "Epidemiological and genetic correlates of severe acute respiratory syndrome coronavirus infection in the hospital with the highest nosocomial infection rate in Taiwan in 2003," Journal of Clinical Microbiology, vol. 44, no. 2, pp. 359-365, 2006.

[28] S. F. Wang, K. H. Chen, M. Chen et al., "Human-leukocyte antigen class I Cw 1502 and class II DR 0301 genotypes are associated with resistance to severe acute respiratory syndrome (SARS) infection," Viral Immunology, vol. 24, no. 5, pp. 421-426, 2011.

[29] H. Hofmann and S. Pöhlmann, "Cellular entry of the SARS coronavirus," Trends in Microbiology, vol. 12, no. 10, pp. 466-472, 2004.

[30] W. Li, M. J. Moore, N. Vasilieva et al., "Angiotensin-converting enzyme 2 is a functional receptor for the SARS coronavirus," Nature, vol. 426, no. 6965, pp. 450-454, 2003.

[31] S. A. Jeffers, S. M. Tusell, L. Gillim-Ross et al., "CD209L (LSIGN) is a receptor for severe acute respiratory syndrome 
coronavirus," Proceedings of the National Academy of Sciences of the United States of America, vol. 101, no. 44, pp. 1574815753, 2004.

[32] Z. Y. Yang, Y. Huang, L. Ganesh et al., "pH-dependent entry of severe acute respiratory syndrome coronavirus is mediated by the spike glycoprotein and enhanced by dendritic cell transfer through DC-SIGN," Journal of Virology, vol. 78, no. 11, pp. 5642-5650, 2004.

[33] R. W. K. Chiu, N. L. S. Tang, D. S. C. Hui et al., "ACE2 gene polymorphisms do not affect outcome of severe acute respiratory syndrome," Clinical Chemistry, vol. 50, no. 9, pp. 16831686, 2004.

[34] S. Itoyama, N. Keicho, M. Hijikata et al., "Identification of an alternative 5 -untranslated exon and new polymorphisms of angiotensin-converting enzyme 2 gene: lack of association with SARS in the Vietnamese population," American Journal of Medical Genetics. Part A, vol. 136, no. 1, pp. 52-57, 2005.

[35] T. J. Braciale and Y. S. Hahn, "Immunity to viruses," Immunological Reviews, vol. 255, no. 1, pp. 5-12, 2013.

[36] C. A. Biron, "Role of early cytokines, including alpha and beta interferons (IFN-alpha/beta), in innate and adaptive immune responses to viral infections," Seminars in Immunology, vol. 10, no. 5, pp. 383-390, 1998.

[37] M. P. Martin and M. Carrington, "Immunogenetics of viral infections," Current Opinion in Immunology, vol. 17, no. 5, pp. 510-516, 2005.

[38] J. M. Blackwell, S. E. Jamieson, and D. Burgner, "HLA and infectious diseases," Clinical Microbiology Reviews, vol. 22, no. 2, pp. 370-385, 2009.

[39] D. Burgner, S. E. Jamieson, and J. M. Blackwell, "Genetic susceptibility to infectious diseases: big is beautiful, but will bigger be even better?," The Lancet Infectious Diseases, vol. 6, no. 10, pp. 653-663, 2006.

[40] R. H. Xu, J. F. He, M. R. Evans et al., "Epidemiologic clues to SARS origin in China," Emerging Infectious Diseases, vol. 10, no. 6, pp. 1030-1037, 2004.

[41] O. Ramos-Lopez, E. Martinez-Lopez, S. Roman, N. A. Fierro, and A. Panduro, "Genetic, metabolic and environmental factors involved in the development of liver cirrhosis in Mexico," World Journal of Gastroenterology, vol. 21, no. 41, pp. 1155211566, 2015.

[42] K. Offit, "Personalized medicine: new genomics, old lessons," Human Genetics, vol. 130, no. 1, pp. 3-14, 2011.

[43] L. Goni, M. Cuervo, F. I. Milagro, and J. A. Martínez, "Future perspectives of personalized weight loss interventions based on nutrigenetic, epigenetic, and metagenomic data," The Journal of Nutrition, vol. 146, no. 4, pp. 905S-912S, 2015.

[44] P. Conti, C. E. Gallenga, G. Tetè et al., "How to reduce the likelihood of coronavirus-19 (CoV-19 or SARS-CoV-2) infection and lung inflammation mediated by IL-1," Journal of Biological Regulators and Homeostatic Agents, vol. 34, 2020.

[45] F. M. Buonaguro, I. Puzanov, and P. A. Ascierto, "Anti-IL6R role in treatment of COVID-19-related ARDS," Journal of Translational Medicine, vol. 18, no. 1, p. 165, 2020.

[46] C. Yin, "Genotyping coronavirus SARS-CoV-2: methods and implications," Genomics, vol. 112, no. 5, pp. 3588-3596, 2020.

[47] K. Y. K. Chan, M. S. Xu, J. C. Y. Ching et al., "CD209 (DCSIGN) $-336 \mathrm{~A}>\mathrm{G}$ promoter polymorphism and severe acute respiratory syndrome in Hong Kong Chinese," Human Immunology, vol. 71, no. 7, pp. 702-707, 2010.
[48] K. Y. Chan, M. S. Xu, J. C. Ching et al., “Association of a single nucleotide polymorphism in the CD209 (DC-SIGN) promoter with SARS severity," Hong Kong Medical Journal, vol. 16, 5 Supplement 4, pp. 37-42, 2010.

[49] U. S. Khoo, K. Y. Chan, J. C. Y. Ching et al., "Functional role of ICAM-3 polymorphism in genetic susceptibility to SARS infection," Hong Kong Medical Journal, vol. 15, Supplement 6, pp. 26-29, 2009.

[50] K. Y. K. Chan, J. C. Y. Ching, M. S. Xu et al., "Association of ICAM3 genetic variant with severe acute respiratory syndrome," The Journal of Infectious Diseases, vol. 196, no. 2, pp. 271-280, 2007.

[51] M. W. Ng, G. Zhou, W. P. Chong et al., "The association of RANTES polymorphism with severe acute respiratory syndrome in Hong Kong and Beijing Chinese," BMC Infectious Diseases, vol. 7, no. 1, p. 50, 2007.

[52] J. He, D. Feng, S. J. de Vlas et al., “Association of SARS susceptibility with single nucleic acid polymorphisms of OAS1 and MxA genes: a case-control study," BMC Infectious Diseases, vol. 6, no. 1, p. 106, 2006.

[53] H. W. Wang, J. He, P. H. Zhang et al., "A case-control study on the mxA polymorphisms and susceptibility to severe acute respiratory syndromes," Zhonghua Liu Xing Bing Xue Za Zhi, vol. 26, no. 8, pp. 574-577, 2005.

[54] F. Tang, W. Liu, F. Zhang et al., "IL-12 RB1 genetic variants contribute to human susceptibility to severe acute respiratory syndrome infection among Chinese," PLoS One, vol. 3, no. 5, article e2183, 2008.

[55] F. F. Yuan, J. Tanner, P. K. S. Chan et al., "Influence of FcgammaRIIA and MBL polymorphisms on severe acute respiratory syndrome," Tissue Antigens, vol. 66, no. 4, pp. 291-296, 2005.

[56] H. Zhang, G. Zhou, L. Zhi et al., "Association between mannose-binding lectin gene polymorphisms and susceptibility to severe acute respiratory syndrome coronavirus infection," The Journal of Infectious Diseases, vol. 192, no. 8, pp. 1355-1361, 2005.

[57] X. Tu, W. P. Chong, Y. Zhai et al., "Functional polymorphisms of the CCL2 and MBL genes cumulatively increase susceptibility to severe acute respiratory syndrome coronavirus infection," The Journal of Infection, vol. 71, no. 1, pp. 101-109, 2015.

[58] X. Zhu, Y. Wang, H. Zhang et al., "Genetic variation of the human $\alpha$-2-Heremans-Schmid glycoprotein (AHSG) gene associated with the risk of SARS-CoV infection," PLoS One, vol. 6, no. 8, article e23730, 2011.

[59] M. H. Ng, S. H. Cheng, K. M. Lau et al., "Immunogenetics in SARS: a case-control study," Hong Kong Medical Journal, vol. 16, 5 Supplement 4, pp. 29-33, 2010.

[60] N. Keicho, S. Itoyama, K. Kashiwase et al., "Association of human leukocyte antigen class II alleles with severe acute respiratory syndrome in the Vietnamese population," Human Immunology, vol. 70, no. 7, pp. 527-531, 2009. 